\title{
A multi-criteria decision making approach in lighting technology selection for a production hall
}

\author{
Maria Cristea ${ }^{1, *}$, Radu Adrian Tîrnovan ${ }^{2}$, Ciprian Cristea $^{3}$, and Constantin Sorin Pică ${ }^{4}$ \\ ${ }^{1}$ Technical University of Cluj-Napoca, Faculty of Electrical Engineering, fagarasan maria@yahoo.com, România \\ ${ }^{2}$ Technical University of Cluj-Napoca, Faculty of Electrical Engineering, radu.tirnovan@enm.utcluj.ro, România \\ ${ }^{3}$ Technical University of Cluj-Napoca, Faculty of Electrical Engineering, ciprian.cristea@emd.utcluj.ro, România \\ ${ }^{4}$ Technical University of Cluj-Napoca, Faculty of Electrical Engineering, sorin.pica@enm.utcluj.ro, România
}

\begin{abstract}
Nowadays, lighting industry can contribute to a more sustainable future, by reducing the total consumption of electrical energy used to illuminate indoor and outdoor spaces. Thus, lighting system design is one of the important components when thinking about building sustainability. Taking into account the final purpose of the lighting installation (the type of human activity that will take place in the indoor space for which lighting is to be provided), the most suitable lighting technologies are selected considering their characteristics, dimensions, and technical specification. The paper presents how a lighting technology selection for a production hall using a multi-criteria decision making approach. There are considered the most common luminaires and lamps which can assure the illuminance necessary for the hall, which represent the variants, evaluated against several criteria, considering the decision maker's preferences and constraints. The variants are ranked according to their performance for each criterion. The optimal lighting solution obtained after the simulation experiment suggests that ELECTRE III method is a practical decision-making model that can be considered for this type of decisions.
\end{abstract}

\section{Introduction}

Lighting system design is one of the most important elements when taking into account building sustainability. In most of the countries with a developed industry, indoor lighting is an important contributor in rising energy cost, because it is used approximately $18 \%$ of the total energy consumption $[1,2]$. There can be considered three main elements that affect the final energy consumption of a lighting system: the lamp (which is the light source and includes controls and ballasts), the luminaire and the indoor environmental quality (the specifications of the room) $[3,4]$. There are different lighting technologies used in indoor spaces, and are compared by three objectives: photometrical performance, energy efficiency and installation performance. Recently, the photometrical performance is frequently considered less important than energy efficiency, which determines poor visual comfort, affecting not only the well-being and satisfaction of the occupants, but also the productivity, and leads to actions with the goal of restoring or preserving the comfort, that can contribute to high energy consumption $[2,5]$.

European standard EN 12665 defines visual comfort as "a subjective condition of visual well-being induced by the visual environment" and includes the following physical factors: "the amount of light", "the uniformity of light", "the quality of light in rendering colours", and "the risk of glare for occupants" [6,7]. These factors can describe the lighting requirements that humans need in different indoor spaces [3]. There are multiple lighting technologies that can satisfy the conditions for visual comfort in indoor environments, regardless the kind of human activities that take place there: each type of luminaire can be combined with different lamps, conventional ones (e.g. incandescent and fluorescent lamps) or light emitting diodes (LED's). Each type of lamp has its own features (power consumption, energy efficiency, degree of protection against different environmental factors, the cost and many other) that have to be taken in consideration when choosing the right luminaire-lamp combination for indoor lighting [2, 8, 9].

Hence, this type of decision implies multiple criteria, and there are several methods that can be used to solve this problem, the most common being: Analytical Hierarchy Process (AHP), Preference Ranking Organisation Method for Enrichment Analysis (PROMETHEE), Elimination and Choice Expressing Reality (ELECTRE), Techniques for Order Performance by Similarity to Ideal Solution (TOPSIS), and Simple Multi Attribute Rating Technique (SMART) [10]. To select the optimal lighting technology for a production hall, the method ELECTRE III was chosen, using the software created by the authors in [11].

The rest of this paper is organized as follows: Section 2 describes the methodology of the multi-criteria decision-making method; Section 3 presents the case study and are described the alternatives (the luminairelamp combinations that define the technically acceptable

* Corresponding author: fagarasan_maria@yahoo.com 
solutions), the criteria used to rank the alternatives, the decision maker's preference and the existing constrains, and, finally, in Section 4 the results are discussed; in the last section the final conclusions are drawn.

\section{Methodology}

The different versions of ELECTRE methods (ELECTRE I, II, III, IV and TRI) were conceived to solve complex problems, based on various forms of data and inaccurate information, and which have high unpredictability and contradictory objective. All these methods have the same basic principles, but are different from two points of view: operationally and based on the type of the decision problem discussed [12, 13].

The selection of the optimal lighting technology for the production hall is a complex decision problem and there are various criteria that have to be taken into account. Thus, ELECTRE III was chosen for this type of decision because it works with inaccurate, imprecise and uncertain data and takes into account both qualitative and quantitative criteria, then ranks the alternatives from the best to the worst, considering the decision maker's preferences and constraints [14].

The algorithm of the ELECTRE III method consists of the following phases [11-15]:

a) Setting up a set of data - the alternatives and the criteria, used to compare the performance for each alternative, are defined; having these two important elements, the performance matrix can be developed. In order to determine outranking relations with a tolerance for imprecise and uncertain data, for each criterion $(i)$ are associated three thresholds: indifference $\left(q_{i}\right)$, preference $\left(p_{i}\right)$, and veto $\left(v_{i}\right)$. At last, the weight indexes $\left(w_{i}\right)$ are defined, which express the importance that the decision maker assigns to each criterion.

b) Establishing the outranking relations - to determine outranking relations between the variants with respect to each criterion there are formed successive pair wise comparisons of two alternatives. The computation procedure includes three tests: concordance, discordance and credibility test.

In the first test are estimated the concordance index for each pair of alternatives by comparing the performance of both variants for all criteria, based on the statement "variant $(a)$ outranks variant $(b)$ "; the value of concordance index is between 0 (the statement is false) and 1 (the statement is true) and in the process are used both indifference and preference thresholds. The global indicators, which form the concordance matrix, are obtain as the weighted sum of all concordance indexes for the considered criteria.

The second test quantifies the strength of the evidence against the statement "variant $(a)$ outranks variant $(b)$ ", obtaining the discordance indexes. In order to estimate this outranking relation, the veto threshold needs to be used. If there is not a veto threshold assigned to each criterion by the decision maker, the discordance indexes are null, so there is no need to perform the next test, because the concordance matrix is the same as the credibility matrix.
In the final test the degrees of credibility are calculated, taking into account the concordance indicators and the discordance indexes estimated in the previous tests. The values of the credibility degrees are between 0 and 1 , and they compose the credibility matrix, which is used in the next phase.

c) Implementation of the outranking relations - after the credibility matrix is obtained, the distillation procedures can be performed. Thus, the alternatives are ranked depending on their performances in two pre-orders: descending distillation is constructed by selecting the best ranked variant, called the first distillate $\left(D_{1}\right)$, and finishing with the worst, and ascending distillation is acquired by selecting the worst rated variants and finishing with the best one.

The results obtained after these two procedures (descending distillation and ascending distillation) are combined into a final ranking, which will return the final result in a ranking matrix or in an outranking graph. The optimal solution is the best rated alternative, considering all the criteria used in the analysis.

\section{Case study}

In order to achieve a correct interior lighting design, an initial set of data is required for the room in which the lighting installation is designed: dimensions: width $\left(L_{l}\right)$, length $\left(L_{2}\right)$, height $(H)$ and height of working plane $\left(h_{u}\right)$; room reflectance: walls reflectance $\left(\rho_{p}\right)$, ceiling reflectance $\left(\rho_{t}\right)$ and floor reflectance $\left(\rho_{s}\right)$; average illuminance, minimum $\left(E_{m e d}\right)$.

For this study, a production hall with the following features has been considered:

a) Dimensions: $\mathrm{L}_{1}=10 \mathrm{~m}, \mathrm{~L}_{2}=20 \mathrm{~m}, \mathrm{H}=7 \mathrm{~m}, \mathrm{~h}_{\mathrm{u}}=0,8 \mathrm{~m}$;

b) Room reflectance: $\rho_{\mathrm{p}}=0,5, \rho_{\mathrm{t}}=0,7, \rho_{\mathrm{s}}=0,3$;

c) $\mathrm{E}_{\text {med }}=300 \mathrm{~lx}$.

In order to determine the possible technical solutions that satisfy the lighting conditions for the production hall, there have been selected four luminaires, which were combined with different types of lamps, fluorescent lamps and LEDs, and each one with different wattage. At this point there are hundreds of possible solutions that can be considered. To obtain only the acceptable ones, the utilisation factor $(u)$ method was applied. This factor depends on the room index and room reflectance. The room index $(i)$ is determined as the division between room area and the product of the height of luminaire above working plane $(h)$ and the length and width of the room. After the utilisation factors are determined, the acceptable technical solutions, which represent the alternatives, can be defined. These are presented in Table 1.

There are eight luminaire-lamp combinations that can provide the lighting conditions for the production hall. The first four possible solutions are using the MATIS FIRA 03 luminaire, which is manufactured by Elba and has an output of $64 \%$, in combination with four types of lamps: MASTER TL-D Reflex 2x36W/840, MASTER TL-D Reflex 2x58W/840, MASTER LEDtube Universal 
Table 1. The set of alternatives.

\begin{tabular}{|c|c|c|c|c|}
\hline \multicolumn{3}{|c|}{ Calculated data } & \multicolumn{2}{|c|}{ Alternatives } \\
\hline $\begin{array}{c}h \\
{[m]}\end{array}$ & $i$ & $u$ & $\begin{array}{c}\text { Luminaire } \\
\text { type }\end{array}$ & Lamp type \\
\hline \multirow{8}{*}{6.2} & \multirow{8}{*}{1} & 0.5 & $\begin{array}{l}\text { MATIS - } \\
\text { FIRA } 03\end{array}$ & $\begin{array}{l}\text { MASTER TL-D } \\
\text { Reflex } 2 \times 36 \mathrm{~W} / 840\end{array}$ \\
\hline & & 0.5 & $\begin{array}{l}\text { MATIS - } \\
\text { FIRA } 03\end{array}$ & $\begin{array}{l}\text { MASTER TL-D } \\
\text { Reflex } 2 \times 58 \mathrm{~W} / 840\end{array}$ \\
\hline & & 0.5 & $\begin{array}{l}\text { MATIS - } \\
\text { FIRA } 03\end{array}$ & $\begin{array}{c}\text { MASTER LEDtube } \\
\text { Universal T8 } \\
2 \times 24 \mathrm{~W} / 840\end{array}$ \\
\hline & & 0.5 & $\begin{array}{l}\text { MATIS - } \\
\text { FIRA } 03\end{array}$ & $\begin{array}{c}\text { MASTER LEDtube } \\
\text { Universal T8 } \\
2 \times 16 \mathrm{~W} / 840\end{array}$ \\
\hline & & 0.51 & TCS165 & $\begin{array}{l}\text { MASTER TL5 HE } \\
2 \times 28 \mathrm{~W} / 840\end{array}$ \\
\hline & & 0.46 & TCS165 & $\begin{array}{c}\text { MASTER TL5 HE } \\
2 \times 35 \mathrm{~W} / 840\end{array}$ \\
\hline & & 0.36 & TCW060 & $\begin{array}{l}\text { MASTER TL-D } \\
\text { Reflex } 2 \times 36 \mathrm{~W} / 840\end{array}$ \\
\hline & & 0.34 & TCW060 & $\begin{array}{l}\text { MASTER TL-D } \\
\text { Reflex } 2 \times 58 \mathrm{~W} / 840\end{array}$ \\
\hline
\end{tabular}

T8 2x24W/840 and MASTER LEDtube Universal T8 $2 \times 16 \mathrm{~W} / 840$.

MASTER TL-D Reflex, is a conventional source, a fluorescent tube, that directs most of the light were is necessary, thanks to an internal reflector and the result is the same level of illumination, while half of the number of lamps in the luminaire are used; other benefits include the fact that the internal reflector is not affected by dust accumulation (compared to normal TL-D sources) and the efficiency is relatively high, both initially and during its lifetime, with a luminous flux constant. The wattages used for this lamp are $36 \mathrm{~W}$ and $58 \mathrm{~W}$.

MASTER LEDtube Universal T8 is a LED tube and is uniquely designed to allow the direct fitting of the lamp into luminaires, which operate either on electromagnetic ballasts or on high-frequency electronic ballasts or with a direct connection to the electrical network; other benefits include low operating costs, due to lower energy consumption, and lower maintenance costs, thanks to longer lifetime than conventional lamps. The wattages used for this type of lamp are $24 \mathrm{~W}$ and 16W.

The next two possible solutions use the TCS165 luminaire, which is manufactured by Philips and has an output of $69 \%$ for the lamp with $28 \mathrm{~W}$ and $62 \%$ for the lamp with $35 \mathrm{~W}$. The type of lamp used is MASTER TL5 HE, which is a conventional source, a fluorescent tube. It has a high luminous efficiency, which results in low energy consumption, while ensuring excellent light output and good colour rendering. Other benefits include easy fastening in ceiling module systems and the high efficiency of the lamp and the luminaire to which it attaches. The wattages selected for this type of lamp are $28 \mathrm{~W}$ and $35 \mathrm{~W}$.

The last two possible solutions use the TCW060 luminaire, which is also manufactured by Philips, and has the lowest output of all luminaires used in this study: 59\% for the lamp with $58 \mathrm{~W}$ and $63 \%$ for the one with $36 \mathrm{~W}$. The type of lamp used in combination with this luminaire is MASTER TL-D Reflex (fluorescent tube), which is the same as the one used in combination with the first luminaire, MATIS - FIRA 03.

For this case study, eight criteria were proposed in order to perform a complete evaluation of the luminairelamp combinations selected using the utilisation factor method.

The first criterion is the energy consumption $\left(q_{e}-\right.$ $[\mathrm{kWh} / 1000 \mathrm{~h}])$ of the whole lighting installation required to provide the minimum, average illuminance. For this, there has to be determined the number of luminaires $\left(N_{c}\right)$, calculated with the following relation:

$$
N_{c}=\frac{L_{1} \cdot L_{2} \cdot E_{m e d}}{u \cdot N_{l c} \cdot \Phi_{l}}
$$

where:

$N_{c}$ - number of luminaires required [pcs];

$L_{l}$ - width of the production hall [m];

$L_{2}$ - length of the production hall [m];

$E_{\text {med }}-$ minimum, average illuminance [lx];

$u$ - utilisation factor;

$N_{l c}$ - number of lamps in luminaire [pcs];

$\Phi_{l}-$ initial lamp output $[\mathrm{lm}]$.

To determine the total energy consumption, the following formula is used :

$$
q_{e}=N_{l c} \cdot q_{e l} \cdot N_{c}
$$

where:

$q_{e}-$ total energy consumption of all luminaires $[\mathrm{kWh} / 1000 \mathrm{~h}]$;

$N_{l c}$ - number of lamps in luminaire [pcs];

$q_{e l}-$ energy consumption of the lamp $[\mathrm{kWh} / 1000 \mathrm{~h}]$;

$N_{c}$ - number of luminaires required [pcs].

Another criterion used to evaluate the selected alternatives is luminous efficiency $\left(E_{c}\right)$, which is directly related to energy consumption: the higher efficiency the lower energy usage will be, and is determined as division between the lamp luminous flux and the power consumed by the lamp. The unit used for the efficiency is lumens per watt $([\mathrm{lm} / \mathrm{W}])$.

The luminaires require protection against different external factors, therefor the manufacturer specifies the following degrees of protection for each type of luminaire: "Ingress Protection" (IP) system indicates the level of protection to ingress of foreign solid objects, such as dust, and moisture; the degree of external mechanical impact protection $(I K)$ reflects the property of the luminaire to maintain integrity after being subjected to mechanical shock without affecting the operation of the electrical circuit and without compromising its security. This two criteria, IP and IK protection ([points]) should be assessed carefully in order to keep the maintenance cost at a reasonable level.

The total price of the lighting system $\left(\operatorname{Pr}_{S}-[\mathrm{RON}]\right)$ may slightly vary, depending on the supplier's pricing 
policy in relation to its partners. The formula used to determine the total price is:

$$
\operatorname{Prs}=N_{c} \cdot\left(\operatorname{Prcil}_{c i l}+N_{l c} \cdot \operatorname{Prl}\right)
$$

where:

$\mathrm{Pr}_{S}$ - total price of the lighting system [RON];

$N_{c}$ - number of luminaires required [pcs];

$P r_{c i l}-$ price of the luminaire [RON];

$N_{l c}$ - number of lamps in luminaire [pcs];

$P r_{l}$ - price of the lamp [RON].

Another criterion is the installation price $\left(\mathrm{Pr}_{i}-\right.$ $[\mathrm{RON}]$ ) and is determined as the product between the number of the luminaires required and the unit cost of installation. In this study, the unit cost of installation has been considered to be $4.43 \mathrm{RON}$, on the assumption that the installation of a luminaire lasts about 30 minutes and the person responsible for this activity has a remuneration of 1450 RON per month.
The last two criteria, lamp lifetime ([h]) and lamp warranty ([months]), differs depending on the lamp type, if it is an incandescent or fluorescent lamp, or light emitting diode (LED). The lamp lifetime reflects the hours of operation under normal conditions, without taking into account the negative effects that may occur in the network and which may contribute to more rapid degradation of the source. The lamp warranty granted on purchase protects the customers from possible defective products. The values for these two indicators are specified by the manufacturer in the data sheet of the product.

The decision matrix, which represents the performance of all alternatives to be evaluated with respect to the identified criteria, is presented in Table 2 . The weights and the values for each threshold are given in Table 3.

Table 2. Performance matrix.

\begin{tabular}{|c|c|c|c|c|c|c|c|c|}
\hline Criteria & $\begin{array}{c}\text { Energy } \\
\text { consumption } \\
\text { Alternatives }\end{array}$ & $\begin{array}{c}\text { Luminous } \\
\text { efficiency } \\
{[\mathbf{I m} / \mathbf{W}]}\end{array}$ & $\begin{array}{c}\text { IP } \\
{[\text { [points] }}\end{array}$ & $\begin{array}{c}\text { IK } \\
{[\text { [points] }}\end{array}$ & $\begin{array}{c}\text { Lighting } \\
\text { system price } \\
{[\mathbf{R O N}]}\end{array}$ & $\begin{array}{c}\text { Installation } \\
\text { price } \\
{[\mathbf{R O N}]}\end{array}$ & $\begin{array}{c}\text { Lamp } \\
\text { lifetime } \\
{[\mathbf{h}]}\end{array}$ & $\begin{array}{c}\text { Lamp } \\
\text { warranty } \\
{[\mathbf{m o n t h s}]}\end{array}$ \\
\hline FIRA03_FL_36W & 2352 & 93.06 & 40 & 7 & 10296.16 & 126.88 & 20000 & 24 \\
\hline FIRA03_FL_58W & 2448 & 89.57 & 40 & 7 & 8306.64 & 81.56 & 20000 & 24 \\
\hline FIRA03_LED_24W & 1248 & 154.17 & 40 & 7 & 11688.04 & 117.81 & 50000 & 60 \\
\hline FIRA03_LED_16W & 1216 & 156.25 & 40 & 7 & 13663.66 & 172.19 & 50000 & 60 \\
\hline TCS165_FL_28W & 1860 & 103.94 & 20 & 2 & 16600.2 & 135.94 & 24000 & 24 \\
\hline TCS165_FL_35W & 2204 & 102.82 & 20 & 2 & 16647.16 & 131.41 & 24000 & 24 \\
\hline TCW060_FL_36W & 3360 & 93.06 & 65 & 8 & 12388.8 & 181.25 & 20000 \\
\hline TCW060_FL_58W & 3944 & 89.57 & 65 & 8 & 11375.54 & 131.41 & 20000 \\
\hline
\end{tabular}

Table 3. Thresholds and criteria weights.

\begin{tabular}{|c|c|c|c|c|c|c|c|c|}
\hline $\begin{array}{c}\text { Weights Criteria } \\
\text { Thresholds }\end{array}$ & $\begin{array}{c}\text { Energy } \\
\text { consumption } \\
{[\mathbf{k W h} / \mathbf{1 0 0 0 h}]}\end{array}$ & $\begin{array}{c}\text { Luminous } \\
\text { efficiency } \\
{[\mathbf{I m} / \mathbf{W}]}\end{array}$ & $\begin{array}{c}\text { IP } \\
\text { [points] }\end{array}$ & $\begin{array}{c}\text { IK } \\
\text { [points] }\end{array}$ & $\begin{array}{c}\text { Lighting } \\
\text { system price } \\
{[\mathbf{R O N}]}\end{array}$ & $\begin{array}{c}\text { Installation } \\
\text { price } \\
{[\mathbf{R O N}]}\end{array}$ & $\begin{array}{c}\text { Lamp } \\
\text { lifetime } \\
{[\mathbf{h}]}\end{array}$ & $\begin{array}{c}\text { Lamp } \\
\text { warranty } \\
{[\mathbf{m o n t h}]}\end{array}$ \\
\hline Indifference $(q)$ & 0.05 & 0.1 & 0.2 & 0.1 & 0.05 & 0.1 & 0.1 & 0.15 \\
\hline Preference $(p)$ & 0.15 & 0.25 & 0.3 & 0.2 & 0.1 & 0.25 & 0.3 & 0.3 \\
\hline Veto $(v)$ & 0 & 0 & 0 & 0 & 0 & 0 & 0 & 0 \\
\hline Weight $(w)$ & 0.2 & 0.15 & 0.05 & 0.05 & 0.25 & 0.1 & 0.15 & 0.05 \\
\hline
\end{tabular}

\section{Results}

The computational experiments for this study were performed using the software developed by the authors based on the ELECTRE III method algorithm. The software is a Windows Forms application, built using the tools Microsoft .NET Framework and Visual Studio 2015.
The language used to create the application is $\mathrm{CH}$, version 4.5, which was developed by Microsoft and is a multiparadigm programming language encompassing powerful typing, declarative, functional, imperative and objectoriented programming disciplines. The user interface uses Windows Forms, which is a class library included as part of Microsoft .NET Framework, and offer a lot of flexibility and scalability in gathering and displaying data. 
After the developed software is opened, the criteria and alternatives can be defined. For every criterion, the direction of the preference has to be identified. The direction of the preference indicates if the criterion is increasing, like for example the lamp lifetime (the score of the criterion has to be maximized), or diminishing, like for example the energy consumption (the score of the criterion has to be minimized). The directions of preference for the criteria specified in this case study are presented in figure 1 .

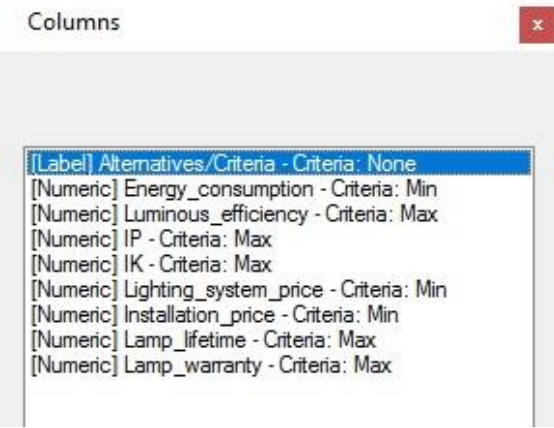

Fig. 1. Directions of preference for the criteria.

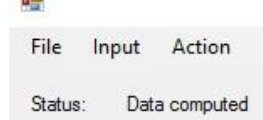

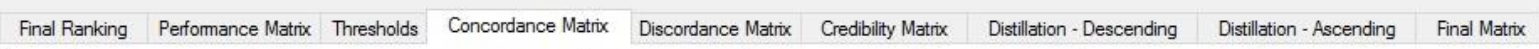

\begin{tabular}{|c|c|c|c|c|c|c|c|c|c|}
\hline & & FIRA03_FL_36W & FIRA03_FL_58W & FIRA03_LED_24W & FIRA03_LED_16W & TCS165_FL_28W & TCS165_FL_35W & TCW060_FL_36W & TCW060_FL_58W \\
\hline \multirow[t]{8}{*}{ 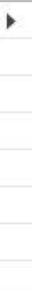 } & FIRA03_FL_36W & 1 & 0.65 & 0.45 & 0.45 & $0.708086180958 \ldots$ & $0.894271086900 \ldots$ & $0.928571428571 \ldots$ & $0.928571428571 \ldots$ \\
\hline & FIRA03_FL_58W & 1 & 1 & 0.45 & 0.45 & $0.664566819247 \ldots$ & $0.777724600688 \ldots$ & $0.928571428571 \ldots$ & $0.928571428571 \ldots$ \\
\hline & FIRA03_LED_24W & 0.75 & 0.65 & 1 & 1 & 1 & 1 & $0.928571428571 \ldots$ & $0.928571428571 \ldots$ \\
\hline & FIRA03_LED_16W & 0.65 & 0.65 & 0.65 & 1 & $0.926317827206 \ldots$ & $0.908779061888 \ldots$ & $0.712056600187 \ldots$ & $0.587350490460 \ldots$ \\
\hline & TCS165_FL_28W & 0.65 & 0.55 & $0.077754891864 \ldots$ & 0.1 & 1 & 1 & 0.65 & 0.65 \\
\hline & TCS165_FL_35W & 0.65 & 0.55 & $0.097671410090 \ldots$ & 0.1 & 0.8 & 1 & 0.65 & 0.65 \\
\hline & TCW060_FL_36W & 0.45 & 0.45 & $0.317180033578 \ldots$ & 0.45 & $0.608095376360 \ldots$ & $0.620121427036 \ldots$ & 1 & $0.741058052434 \ldots$ \\
\hline & TCW060_FL_58W & $0.575569775149 \ldots$ & 0.45 & $0.447671410090 \ldots$ & 0.45 & $0.664566819247 \ldots$ & $0.677071005917 \ldots$ & $0.803853955375 \ldots$ & 1 \\
\hline
\end{tabular}

Fig. 2. Concordance matrix.

Based on the credibility matrix, the two distillation procedures can be performed. In order to rank the alternatives, the software is exploiting the outranking degrees by the descending and ascending distillation procedures, leading to the first complete preclassifications.

The first distillation, descending one, consists of selecting the best ranked alternatives initially and ending with the worst. The best alternative (FIRA03_LED_24W) is taken out from the credibility matrix, and then the procedure is gradually repeated for the remaining alternatives, until all of them are ranked. The result of descending distillation showed preference for FIRA03_LED_24W, followed by FIRA03_FL 58W, FIRA03 FL $36 \mathrm{~W}, \quad$ FIRA03 LED $16 \mathrm{~W}^{-}{ }^{-}$and TCS165_FL_28W. Regarding the last three combinations TCS165 FL 35W, TCW060 FL 36W and TCW060_FL_58W, there was no preference between them. The descending distillation is presented in figure 3 (a).

The ascending distillation, showed in figure 3 (b), uses the same procedure of ranking as the descending one, but with successive removal of the worst alternative.
Once all the alternatives and criteria have been introduced, the user has to define the indifference, preference and veto threshold for each criterion. Table 2 and 3 summarize the data that has been loaded in the application. Complementary results are returned by the software. First, three types of complementary matrices are returned (the concordance matrix, the discordance matrix and the credibility matrix). Figure 2 shows the concordance matrix calculated by the application, which is identical to the credibility matrix because there is no veto threshold and the discordance indexes are zero.

Thus, the ascending distillation illustrated that FIRA03_FL_58W and FIRA03_LED_24W were ranked as the best options, followed closely by FIRA03 FL 36W and FIRA03_LED_16W, on the same place, and on the third place by TCS165 FL 28W. Regarding the alternatives, TCW060_FL_36W and TCW060_FL_58W there was no preference between them. The last ranked combination is TCS165_FL_35W, being on the last place. 
Having the results of the two distillation procedures, the final ranking can be identified by calculating the intersection of the two pre-classifications, as presented in figure 4.

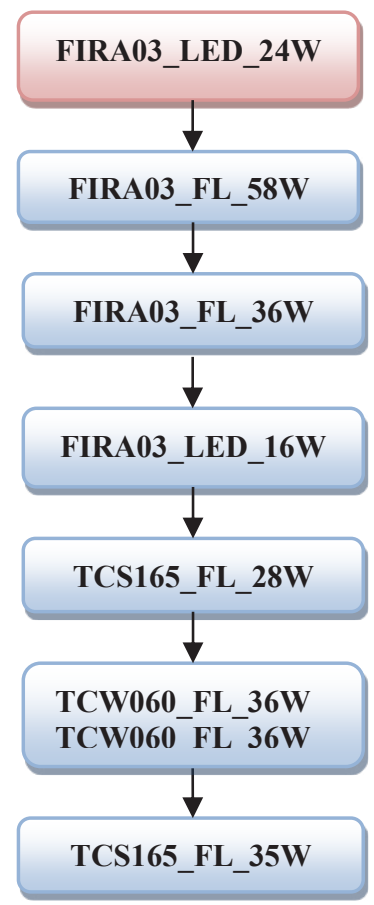

Fig. 4. Final ranking

It can be noticed that FIRA03_LED 24W is the best rated alternative, so it is the optimal lighting solution for the production hall considered in this study. At the other extreme, at the bottom of the ranking, is positioned TCS165_FL_35W, which means that it represents the least preferred luminaire-lamp combination.

\section{Conclusions}

There are different lighting technologies used in indoor spaces, which should be compared by three objectives: photometrical performance, energy efficiency and performance of the installation. For each of these objectives, great consideration should be given, so that either energy consumption or visual comfort would not be affected.

In this paper, a practical application of the ELECTRE III method is proposed to deal both with the quantitative and qualitative criteria and to select the optimal lighting solution suitable for a production hall. Eight luminairelamp combinations have been identified and assessed according to eight criteria that meet the expectations of the beneficiary of the electrical installation project. By running the developed software, the final ranking of the alternatives was obtained. The results reveal that ELECTRE III method may be used in the electrical installations field.

\section{References}

1. A.A. Baloch, P.H. Shaikh, F. Shaikh, Z.H. Leghari, N.H. Mirjat, M.A. Uqaili, Renew. Sust. Energ. Rev., 82, 3007, (2018)

2. F.G. Montoya, A. Peña-Garcia, A. Juaidi, F. Manzano-Agugliaro, Energy Build., 140, 50, (2017)

3. S. Carlucci, F. Causone, F. De Rosa, L. Pagliano, Renew. Sust. Energ. Rev. 47, 1016, (2015)

4. B. Stankovic, A. Kostic, M. Jovanovic Popovic, ESD, 19, 56, (2014)

5. A.M. Atzeri, F. Cappelletti, A. Tzempelikos, A. Gasparella, Energy Build., 127, 411, (2016)

6. N. Makaremi, S. Schiavoni, A.L. Pisello, F. asdrubali, F. Cotana, Energy Procedia, 134, 306, (Energy Build., Chania, Crete, Greece, 2017)

7. Q. Wang, H. Xu, F. Zhang, Z. Wang, Optik, 129, 21, (2017)

8. P. Morgan Pattison, M. Hansen, J.Y. Tsao, C.R. Physique, (2017)

9. I. Kiyak, B. Oral, V. Topuz, Energy Build., 148, 342, (2017)

10. D. Sabaei, J. Erkoyuncu, R. Roy, Procedia CIRP, 37, 30, (2015)

11. M. Cristea, C. Cristea, Proceedings of the Annual Sessions of Scientific Papers "IMT Oradea", XIV, 6, (2015)

12. M.M. Marzouk, Automat. Constr., 20, 596, (2011)

13. C. Cristea, M. Cristea, COSME'16, 4, 9, (2016)

14. D. Neves, P. Baptista, M. Simoes, C.A. Silva, J. Rui Figueira, J. Clean. Prod., 176, 251, (2018)

15. C. Cristea, M. Cristea, COSME'16, 4, 9, (2016) 